\title{
Acute ST-Segment Elevation Myocardial Infarction is Associated with Decreased Human Antimicrobial Peptide LL-37 and Increased Human Neutrophil Peptide-1 to 3 in Plasma
}

\author{
Hanjun Zhao ${ }^{1,2}$, Hongbing Yan ${ }^{1,2}$, Shizuya Yamashita ${ }^{3}$, Wenzheng Li², Chen Liu ${ }^{1}$, Yi Chen², Peng Zhou², \\ Yunpeng $\mathrm{Chi}^{2}$, Shaoping Wang ${ }^{2}$, Bo Zhao ${ }^{2}$ and Li Song ${ }^{1}$
}

\footnotetext{
${ }^{1}$ State Key laboratory of Cadiovascular Disease, Fuwai Hospital, National Center for Cardiovascular Diseases, Chinese Academy of Medical Sciences and Peking Union Medical College, Beijing, China

${ }^{2}$ Department of Cardiology, Beijing Anzhen Hospital, Capital Medical University, Beijing, China

${ }^{3}$ Department of Cardiovascular Medicine, Osaka University Graduate School of Medicine, Osaka, Japan
}

\begin{abstract}
Aim: Increasing evidence indicates that antimicrobial peptides, human neutrophil peptide-1, -2 , and -3 (HNP1-3) and human antimicrobial peptide LL-37 are involved in the pathophysiology of atherosclerosis; however, little is known about their circulating protein levels in acute myocardial infarction (AMI). We therefore investigated whether their plasma levels are associated with stable coronary artery disease (CAD) and acute ST-segment elevation myocardial infarction (STEMI).

Methods: Systemic or local (culprit artery) blood samples were obtained from 112 consecutive male subjects including no CAD $(n=31)$ controls, stable CAD $(n=44)$ and STEMI $(n=47)$. Plasma HNP1-3 and LL-37 levels were measured by the ready-to-use solid-phase enzyme-linked immunosorbent assay (ELISA) based on the sandwich principle.

Results: Systemic HNP1-3 in STEMI was increased compared with no CAD $(p=0.000)$ and stable CAD $(p=0.008)$, and systemic HNP1-3 in stable CAD was higher than in no CAD $(p=0.004)$. Systemic LL-37 in STEMI was decreased compared with no CAD $(p=0.009)$ and stable CAD $(p=0.001)$ and restored within 1 day following STEMI $(p=0.000)$. Local LL-37 levels in STEMI were higher than systemic levels $(p=0.013)$. The areas under the ROC curve of systemic HNP1-3 and LL-37 for STEMI were 0.717 (95\% CI: 0.624, $0.811 ; p=0.000)$ and 0.702 (95\% CI: 0.609, 0.795; $p=0.000)$, respectively. In addition, ischemia time in the STEMI group correlated with systemic and local levels of HNP1-3 ( $r s=-0.360, p=0.013 ; r s=0.608, p=0.000$, respectively), and was also associated with systemic and local levels of hs-CRP ( $r s=0.408, p=0.004 ; r s=0.425, p=0.003$, respectively), but not with those of LL-37 (all $p>0.05$ ).

Conclusion: STEMI was associated with transiently decreased LL-37, but persistently increased HNP1-3 in the systemic circulation and the diagnostic accuracy for STEMI were moderate. Future studies should pay more attention to their prognostic values for myocardial infarction.
\end{abstract}

J Atheroscler Thromb, 2012; 19:357-368.

Key words; HNP1-3; Alpha-defensin; LL-37; Acute myocardial infarction; Inflammation

Address for correspondence: Hongbing Yan, State Key laboratory of Cadiovascular Disease, Fuwai Hospital, National Center for Cardiovascular Diseases, Chinese Academy of Medical Sciences and Peking Union Medical College, No.167, Beilishi

Road, Xicheng District, Beijing 100037,China

E-mail: yan591204@yahoo.com.cn

Received: May 16, 2011

Accepted for publication: October 7, 2011

\section{Introduction}

Emerging evidence indicate that inflammation drives all phases of atherosclerosis, including initiation, progression, and thrombotic complications ${ }^{1)}$. Some inflammatory biomarkers, such as C-reactive protein (CRP), are useful for risk stratification of coronary artery disease $(\mathrm{CAD})^{2)}$; however, systemic levels 
of inflammatory biomarkers do not necessarily correspond with those in the local (culprit) artery ${ }^{3)}$. For example, local levels of serum amyloid A (SAA) at the site of plaque rupture increase relative to the systemic circulation in acute myocardial infarction (AMI), but local CRP levels decrease ${ }^{3)}$. This provides new understanding of their roles in CAD. Recent data suggest that members of acute phase reactants and antimicrobial peptides, human neutrophil peptide-1, -2 , and -3 (HNP1-3, also known as alpha-defensins -1, -2 , and -3/DEFA1-3) and human antimicrobial peptide LL-37 (C-terminus of cathelicidin, also known as human cationic antimicrobial protein/hCAP-18), are also involved in the pathophysiology of atherosclerosis $^{4,5)}$. HNP1-3 participates in lipoprotein metabolism in the vessel wall, favoring low-density lipoprotein (LDL) and lipoprotein(a) [Lp(a)] accumulation or modification in the endothelium and extracellular matrix $^{6,7)}$. It also impairs endothelium-dependent vasorelaxation $^{8)}$, inhibits phenylephrine (PE)-induced artery contraction and PE-mediated $\mathrm{Ca}^{2+}$ mobilization in vascular smooth muscle cells (VSMCs) ${ }^{9)}$, exhibits prothrombotic activity ${ }^{10-12)}$, and plays an inhibitory role in various phases of angiogenesis ${ }^{13)}$. LL-37 upregulates transcription of monocyte chemoattractant protein-1 (MCP-1) and intercellular adhesion molecule-1 (ICAM-1) in cultured human umbilical vein endothelial cells (HUVECs) and induces the death of VSMCs via apoptosis ${ }^{4,5)}$. It also induces endothelium-dependent vessel relaxation, opposite to the action of HNP1-34, 5); however, there is still a lack of data regarding their circulating protein levels in CAD, especially in AMI.

Therefore, we investigated the systemic plasma levels of HNP1-3 and LL-37 in no CAD, stable CAD and acute ST-segment elevation myocardial infarction (STEMI) populations and their time-course changes following STEMI. We also compared their levels at systemic and local sites in STEMI patients. The aim of this study is to investigate whether circulating HNP1-3 and LL-37 levels associate with STEMI.

\section{Materials and Methods}

\section{Study Population}

From July 2009 to December 2009, 112 male patients were involved in this study and categorized into three groups based on their clinical presentation and findings on coronary angiography (CAG): 1) No CAD group. This included 31 patients with chest pain but a smooth coronary angiogram and normal cardiac troponin I (cTnI) levels; 2) Stable CAD group. This included 44 patients with stable CAD confirmed by
CAG who had $\geq 50 \%$ diameter stenosis in the left main (LM) coronary artery or at least one major coronary artery, and displayed normal troponin I levels; and 3) STEMI group. Forty-seven male patients with STEMI underwent successful thrombus aspiration and primary percutaneous coronary intervention (PCI). They had symptoms lasting at least 30 minutes but less than 12 hours with new ST-segment elevation $\geq 0.1 \mathrm{mV}$ in $\geq 2$ contiguous leads and angiographic total occlusion of culprit lesion (TIMI [thrombolysis in myocardial infarction] flow grade 0 or 1 ).

Exclusion criteria: Female and patients with cardiac valve disease, renal failure, liver disease, immune system disease or any identifiable history of infectious disease within two weeks were excluded from this study. STEMI patients with cardiogenic shock or LM occlusion, left bundle branch block, post-fibrinolytic treatment, previous bypass surgery or emergency bypass surgery were not included. The hospital's ethics committee approved the study protocol and informed consent was obtained from each patient.

\section{Procedures and Blood Sampling}

All patients underwent CAG after heparinization (50 units $/ \mathrm{kg}$ ). Blood was aspirated to remove saline from the catheter, and then systemic blood samples ( 4 $\mathrm{mL}$ ) were collected from the aortic root through the catheter before coronary cannulation. In the STEMI group, heparin was added to 100 units/kg before aspiration and intervention. Local blood samples were obtained by aspiration from the site of occlusion as follows: aspiration devices were Diver CE (Invatec, Brescia, Italy) and ZEEK (Zeon Medical Inc., Tokyo, Japan) manual thrombus-aspirating catheters. Materials from the first aspiration were filtered through packaged baskets and $4 \mathrm{~mL}$ blood was collected. If the sample volume was insufficient, filtered blood from the second and/or third aspirations were mixed with the former and then $4 \mathrm{~mL}$ blood was collected. Aspiration catheters were flushed with air before usage to avoid dilution. For the latest 6 STEMI patients, $4 \mathrm{~mL}$ peripheral venous blood was also collected pre-procedure, post-procedure and on days 1, 3, 5 after STEMI. Blood samples were immediately transferred into BD Vacutainer ${ }^{\circledR}$ Heparin Tubes and centrifuged at 3000 rpm for 15 min (Anke, Shanghai, China). Plasma was stored at $-70^{\circ} \mathrm{C}$ for subsequent analysis.

\section{Biochemical Assays}

Assays were performed after the end of patient enrollment. Plasma HNP1-3, LL-37 and high-sensitive CRP (hs-CRP) levels were measured by ready-touse solid-phase enzyme-linked immunosorbent assay 
(ELISA) based on the sandwich principle with commercially available kits, human neutrophil defensins (alpha defensins, HNP1-3) ELISA Kit (HK317) and human LL-37 ELISA Kit (HK321), which were purchased from HyCult Biotechnology (Uden, The Netherlands), and hs-CRP enzyme immunoassay test (48040) which was purchased from RECI Diagnostics $\mathrm{GmbH}$ (Herrenberg, Germany). The assay was performed according to the manufacturer's protocol, and absorbance was measured at $450 \mathrm{~nm}$ using a Thermo Multiskan-MK3 microplate reader (Shanghai, China).

\section{Data Analysis and Statistics}

The characteristics of data distribution were tested by the Kolmogorov-Smirnov test and the homogeneity of variance was tested by Levene's test. Parametric data were expressed as the mean \pm standard deviation (SD). Comparisons between 2 groups were tested by unpaired Student's $t$-test or the paired $t$-test. Comparisons among $\geq 3$ groups were tested by repeated or non-repeated measures ANOVA with a post-hoc test (LSD). Non-parametric data were expressed as medians and interquartile range (IQR). Comparisons between 2 groups were tested by the Mann-Whitney $U$-test or Wilcoxon $t$-test. Comparisons among $\geq 3$ groups were tested by the Kruskal Wallis $H$-test with a post-hoc test (Mann-Whitney $U$-test with Bonferroni correction). Comparisons of frequency between 2 groups were tested by $2 \times 2$ Chi square and Fisher's tests. Comparisons of frequency among $\geq 3$ groups were tested by $\mathrm{m} \times \mathrm{n}$ Chi square and Fisher's tests. Correlation or Spearman's correlation test was used to find associations between two continuous variables. All tests were two-tailed and values of $p<0.05$ were considered significant.

\section{Results}

\section{Patient Characteristics}

Patient characteristics are summarized in Table $\mathbf{1 .}$ The frequency of prior myocardial infarction was higher in the stable CAD group than in the no CAD and STEMI groups $(16 \%$ versus $0 \%$ versus $2 \%$; $p=0.020$ compared with no CAD; $p=0.020$ compared with STEMI, respectively). The frequency of diabetes was higher in STEMI group compared with stable CAD (28\% versus 9\%; $p=0.023$ ), but fasting glucose, lipid profile and $\mathrm{Lp}(\mathrm{a})$ levels did not differ among the three groups. White blood cells (WBC) and subsets were counted before entering the catheterization laboratory. WBC and neutrophil counts were higher in STEMI group than in the no CAD and stable CAD groups (all $p=0.000)$. There were no differ- ences regarding red blood cell counts, platelet counts and hemoglobin levels among the three groups. Angiographic, procedural features and myocardial marker levels in STEMI group are presented in Table 2.

\section{Systemic Levels of Plasma Human Neutrophil Peptide 1-3 and LL-37}

Systemic HNP1-3 levels in the aortic root differed among no CAD, stable CAD and STEMI groups $(110 \mu \mathrm{g} / \mathrm{L}$ [IQR, 89 to $136 \mu \mathrm{g} / \mathrm{L}]$ vs. $133 \mu \mathrm{g} /$ $\mathrm{L}$ [IQR, 125 to $145 \mu \mathrm{g} / \mathrm{L}$ ] vs. $152 \mu \mathrm{g} / \mathrm{L}$ [IQR, 132 to 182] $\mu \mathrm{g} / \mathrm{L}, p=0.000)$. The level in STEMI group was higher than in the other two groups $(p=0.000 \mathrm{com}$ pared with no CAD; $p=0.008$ compared with stable $\mathrm{CAD}$, respectively), and higher in stable $\mathrm{CAD}$ than no CAD $(p=0.004)$. Systemic levels of LL-37 also differed among no CAD, stable CAD and STEMI groups $(27.0 \mu \mathrm{g} / \mathrm{L}$ [IQR, 12.6 to $51.9 \mu \mathrm{g} / \mathrm{L}]$ vs. 26.9 $\mu \mathrm{g} / \mathrm{L}[\mathrm{IQR}, 16.2$ to $65.9 \mu \mathrm{g} / \mathrm{L}]$ vs. $16.6 \mu \mathrm{g} / \mathrm{L}$ [IQR, 7.5 to $25.0 \mu \mathrm{g} / \mathrm{L}], p=0.002)$. Its levels in STEMI group were lower than in the other two groups $(p=0.009$ compared with no CAD; $p=0.001$ compared with stable CAD, respectively). In addition, there was no difference regarding systemic LL-37 levels between no CAD and stable CAD groups $(p=0.702)$ (Fig. 1A).

Local Levels of Plasma Human Neutrophil Peptide 1-3, LL-37 and Highly Sensitive C-Reactive Protein in STEMI Patients

Local levels of HNP1-3 in the culprit artery in STEMI group were similar to systemic levels in the aortic root $(152 \mu \mathrm{g} / \mathrm{L}$ [IQR, 129 to $174 \mu \mathrm{g} / \mathrm{L}]$ vs. 152 $\mu \mathrm{g} / \mathrm{L}$ [IQR, 132 to $182 \mu \mathrm{g} / \mathrm{L}], p=0.775)$, but local LL-37 levels were higher than in the systemic circulation $(20.7 \mu \mathrm{g} / \mathrm{L}$ [IQR, 14.4 to $30.8 \mu \mathrm{g} / \mathrm{L}]$ vs. 16.6 $\mu \mathrm{g} / \mathrm{L}$ [IQR, 7.5 to $25.0 \mu \mathrm{g} / \mathrm{L}], p=0.013$ ) (Fig. 1B). Local and systemic hs-CRP levels were not different $(1.9 \mathrm{mg} / \mathrm{L}[\mathrm{IQR}, 1.1$ to $3.4 \mathrm{mg} / \mathrm{L}]$ vs. $2.1 \mathrm{mg} / \mathrm{L}$ [IQR, 0.9 to $3.5 \mathrm{mg} / \mathrm{L}$ ], $p=0.620$ ) (Fig. 1B). In addition, local LL-37 levels in STEMI group were not different from systemic levels in no CAD and stable CAD groups $(20.7 \mu \mathrm{g} / \mathrm{L}$ [IQR, 14.4 to $30.8 \mu \mathrm{g} / \mathrm{L}$ ] vs. 27.0 $\mu \mathrm{g} / \mathrm{L}$ [IQR, 12.6 to $51.9 \mu \mathrm{g} / \mathrm{L}$ ] vs. $26.9 \mu \mathrm{g} / \mathrm{L}$ [IQR, 16.2 to $65.9 \mu \mathrm{g} / \mathrm{L}], p=0.323$ ) (Fig. 2).

Plasma Human Neutrophil Peptide 1-3, LL-37 and Highly Sensitive C-Reactive Levels in Heralded and Unheralded STEMI

The STEMI group was further divided into two subgroups: unheralded group, which had de novo symptoms of STEMI $(n=30)$, and heralded group, which had symptoms before STEMI $(n=17)$. Angio- 
Table 1. Demographic characters of the subjects

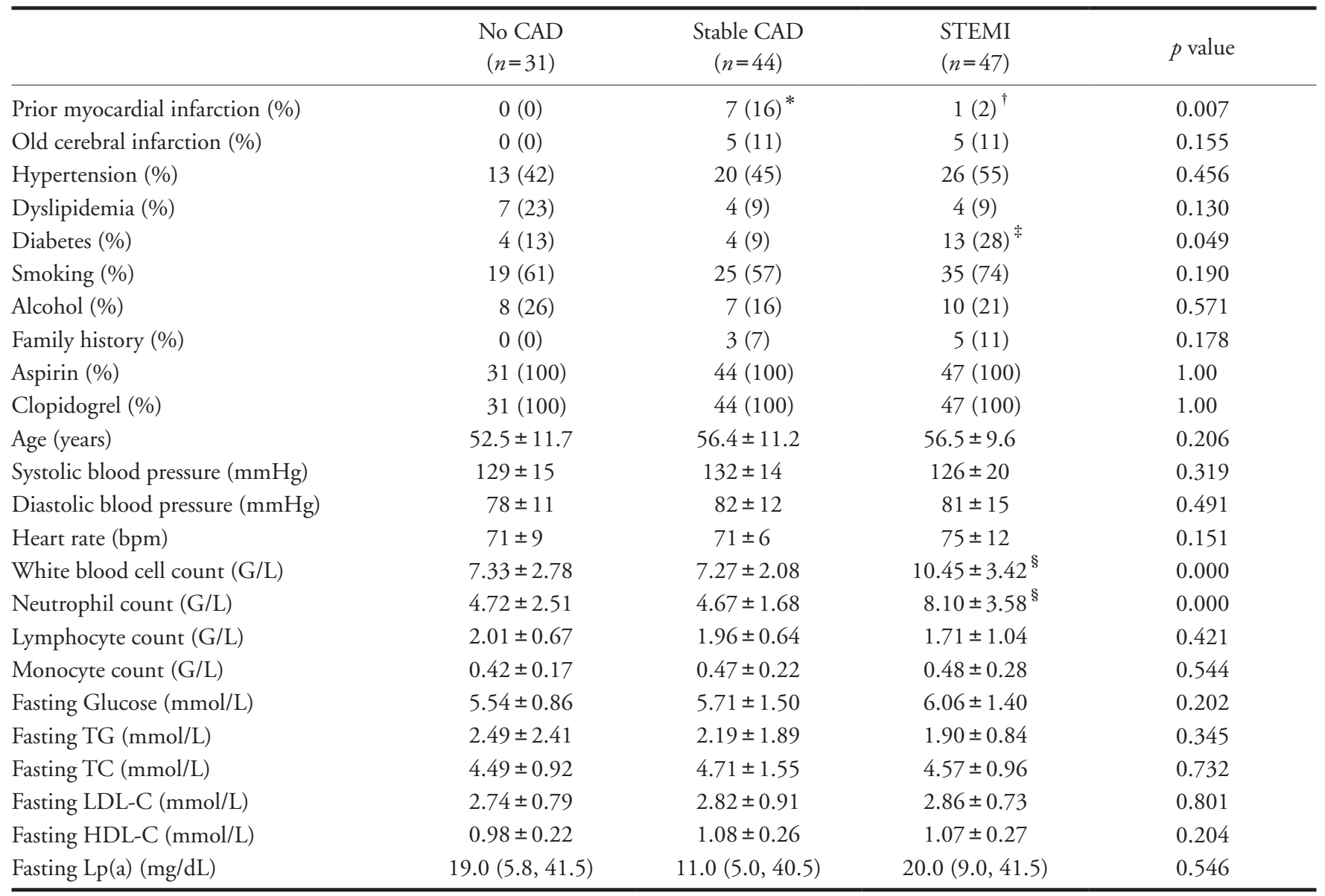

Data are presented as $\mathrm{n}(\%)$, mean $\pm \mathrm{SD}$ or medians and interquartile range. ${ }^{*} p=0.020$ vs. no $\mathrm{CAD} ;{ }^{\dagger} p=0.020$ vs. stable CAD; ${ }^{*} p=0.023$ vs. stable CAD; ${ }^{\S} p=0.000$ vs. other two groups. TG, triglyceride; TC, total cholesterol; LDL-C, low density lipoprotein cholesterol; HDL-C, high density lipoprotein cholesterol; Lp(a), lipoprotein(a).

Table 2. Angiographic findings, myocardial markers and procedural features of STEMI group

\begin{tabular}{lccc}
\hline & $\begin{array}{c}\text { STEMI } \\
(n=47)\end{array}$ & $\begin{array}{c}\text { STEMI } \\
(n=47)\end{array}$ \\
\hline Infarct-related artery & & Average stent number & $1.4 \pm 0.5$ \\
LM (\%) & $0(0)$ & Average stent diameter $(\mathrm{mm})$ & $3.1 \pm 0.4$ \\
LAD (\%) & $26(55)$ & Lesion length $(\mathrm{mm})$ & $30.4 \pm 11.7$ \\
LCX (\%) & $17(36)$ & Post-dilation $(\%)$ & $11(23)$ \\
RCA (\%) & $4(9)$ & Pre-procedure CK $(\mathrm{U} / \mathrm{L})$ & $504 \pm 742$ \\
Diseased vessels & & Pre-procedure CK-MB $(\mu \mathrm{g} / \mathrm{L})$ & $60 \pm 142$ \\
1 & $14(30)$ & Pre-procedure cTnI $(\mu \mathrm{g} / \mathrm{L})$ & $10.2 \pm 21.6$ \\
2 & $18(38)$ & Peak CK $(\mathrm{U} / \mathrm{L})$ & $2649 \pm 1896$ \\
$\geq 3$ & $15(32)$ & Peak CK-MB $(\mu \mathrm{g} / \mathrm{L})$ & $226 \pm 203$ \\
Onset to aspiration $(\min )$ & $263 \pm 174$ & Peak cTnI $(\mu \mathrm{g} / \mathrm{L})$ & $102 \pm 97$ \\
Direct stenting $(\%)$ & $35(74)$ & & \\
\hline
\end{tabular}

Data are presented as $\mathrm{n}(\%)$ or the mean \pm SD. LM: left main artery; LAD: left anterior descending artery; LCX: left circumflex artery; RCA: right coronary artery. 
A

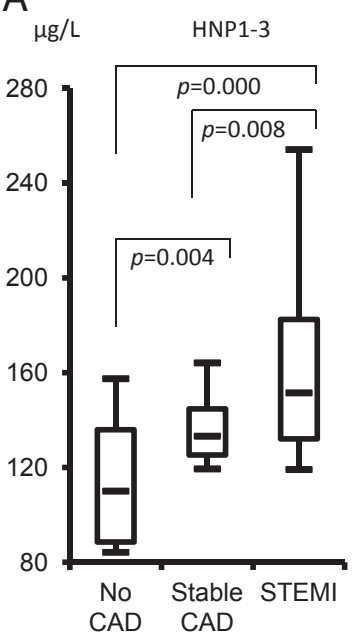

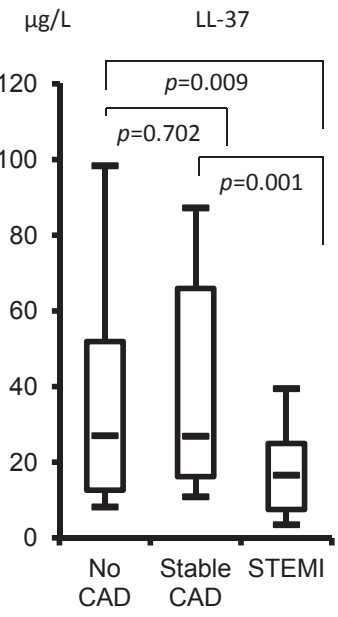

B
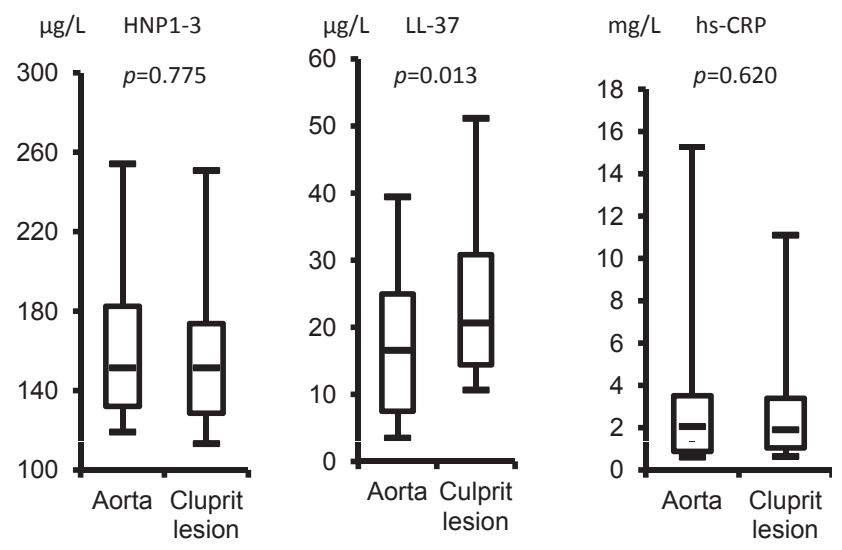

Fig. 1. Panel A: Comparisons of plasma HNP1-3 or LL-37 among no CAD $(n=31)$, stable CAD $(n=44)$ and STEMI $(n=47)$ groups. Panel B: Comparisons of plasma HNP1-3, LL-37 or hs-CRP between systemic and local sites in STEMI $(n=47)$. Medians and 10th, 25th, 75th and 90th percentiles are shown.

graphic findings, myocardial markers and procedural features did not differ between the two groups, except that the former had a longer lesion than the latter $(35.9 \pm 13.2$ vs. $27.3 \pm 9.6 \mathrm{~mm}, p=0.013)$ (Table 3).

Systemic or local levels of plasma HNP1-3, LL-37 and hs-CRP levels did not differ between heralded and unheralded STEMI groups (all $p>0.05$ ) (Fig.3). In the unheralded group, local LL-37 levels were higher than systemic levels $(20.9 \mu \mathrm{g} / \mathrm{L}$ [IQR, 16.0 to $31.2 \mu \mathrm{g} / \mathrm{L}$ ] vs. $15.1 \mu \mathrm{g} / \mathrm{L}$ [IQR, 5.4 to $22.7 \mu \mathrm{g} / \mathrm{L}$ ], $p=0.007)$, but there were no differences regarding local and systemic HNP1-3 levels $(153 \mu \mathrm{g} / \mathrm{L}$ [IQR, 128 to $170 \mu \mathrm{g} / \mathrm{L}$ ] vs. $155 \mu \mathrm{g} / \mathrm{L}$ [IQR, 137 to $193 \mu \mathrm{g} / \mathrm{L}$ ], $p=0.600)$ or hs-CRP levels $(1.8 \mathrm{mg} / \mathrm{L}$ [IQR, 0.9 to $2.8 \mathrm{mg} / \mathrm{L}$ ] vs. $2.0 \mathrm{mg} / \mathrm{L}$ [IQR, 0.9 to $2.9 \mathrm{mg} / \mathrm{L}$ ],

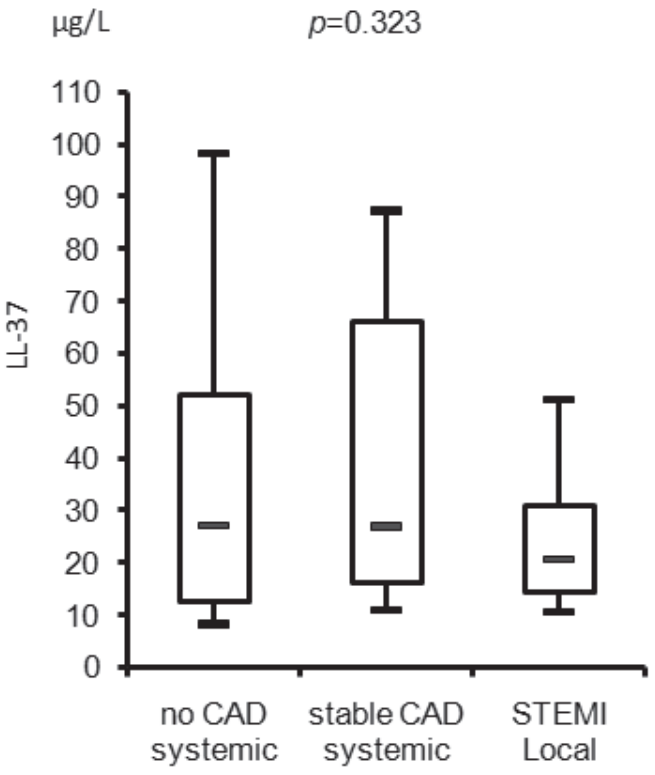

Fig. 2. Comparison of local plasma LL-37 levels in STEMI $(n=47)$ with systemic levels in no CAD $(n=31)$ and stable CAD groups $(n=44)$.

$p=0.782$ ) (Fig. 4A). In the heralded STEMI group, no differences were found between local and systemic levels with respect to HNP1-3 (143 $\mu \mathrm{g} / \mathrm{L}$ [IQR, 131 to $242 \mu \mathrm{g} / \mathrm{L}$ ] vs. $147 \mu \mathrm{g} / \mathrm{L}$ [IQR, 128 to $157 \mu \mathrm{g} / \mathrm{L}$ ], $p=0.255), \mathrm{LL}-37(20.7 \mu \mathrm{g} / \mathrm{L}$ [IQR, 10.9 to $26.6 \mu \mathrm{g} /$ $\mathrm{L}]$ vs. $21.6 \mu \mathrm{g} / \mathrm{L}$ [IQR, 11.4 to $25.6 \mu \mathrm{g} / \mathrm{L}], p=0.276$ ) or hs-CRP $(3.1 \mathrm{mg} / \mathrm{L}$ [IQR, 1.2 to $10.1 \mathrm{mg} / \mathrm{L}]$ vs. 3.3 $\mathrm{mg} / \mathrm{L}$ [IQR, 0.9 to $12.2 \mathrm{mg} / \mathrm{L}], p=0.682$ ) (Fig. 4B).

\section{Time Lapse of Systemic Plasma Human Neutrophil Peptide 1-3, LL-37 and Highly Sensitive C-Reactive Protein Levels}

Systemic (peripheral venous) plasma concentrations of HNP1-3, LL-37 and hs-CRP were measured pre-procedure, post-procedure and on days 1, 3 and 5 following STEMI in the latest six patients. HNP1-3 levels did not differ among those time points (169 \pm $24 \mu \mathrm{g} / \mathrm{L}$ vs. $153 \pm 23 \mu \mathrm{g} / \mathrm{L}$ vs. $176 \pm 21 \mu \mathrm{g} / \mathrm{L}$ vs. $166 \pm$ $30 \mu \mathrm{g} / \mathrm{L}$ vs. $160 \pm 16 \mu \mathrm{g} / \mathrm{L}, p=0.522)$, but LL-37 levels rose from day 1 and were sustained until day 5 $(21.8 \pm 14.2 \mu \mathrm{g} / \mathrm{L}$ vs. $21.4 \pm 12.9 \mu \mathrm{g} / \mathrm{L}$ vs. $65.0 \pm$ $34.5 \mu \mathrm{g} / \mathrm{L}$ vs. $73.2 \pm 21.9 \mu \mathrm{g} / \mathrm{L}$ vs. $64.3 \pm 12.3 \mu \mathrm{g} / \mathrm{L}$, $p=0.000)$ (Fig. 5). In addition, hs-CRP levels rose from day 1, peaked on day 3 and began to fall on day $5(1.5 \pm 0.4 \mathrm{mg} / \mathrm{L}$ vs. $1.4 \pm 0.5 \mathrm{mg} / \mathrm{L}$ vs. $13.2 \pm 7.7$ $\mathrm{mg} / \mathrm{L}$ vs. $24.0 \pm 12.2 \mathrm{mg} / \mathrm{L}$ vs. $11.2 \pm 9.1 \mathrm{mg} / \mathrm{L}, p=$ 0.000) (Fig. 5). 
Table 3. Angiographic findings, myocardial markers and procedural features in heralded and unheralded STEMI groups

\begin{tabular}{|c|c|c|c|}
\hline & $\begin{array}{l}\text { Unheralded } \\
\qquad(n=30)\end{array}$ & $\begin{array}{l}\text { Heralded } \\
(n=17)\end{array}$ & $p$ value \\
\hline Infarct-related artery & & & 0.990 \\
\hline LM (\%) & $0(0)$ & $0(0)$ & \\
\hline LAD (\%) & $12(40)$ & $5(29)$ & \\
\hline LCX (\%) & $2(7)$ & $2(12)$ & \\
\hline RCA (\%) & $16(53)$ & $10(59)$ & \\
\hline Diseased vessels & & & 0.608 \\
\hline 1 & $11(37)$ & $3(18)$ & \\
\hline 2 & $10(33)$ & $8(47)$ & \\
\hline$\geq 3$ & $9(30)$ & $6(35)$ & \\
\hline \multicolumn{4}{|l|}{ Aspiration device } \\
\hline ZEEK/Diver CE & $28 / 2$ & $14 / 3$ & 0.336 \\
\hline Direct stenting (\%) & $23(77)$ & $12(71)$ & 0.912 \\
\hline Onset to aspiration (min) & $244 \pm 170$ & $298 \pm 180$ & 0.310 \\
\hline Stent number & $1.3 \pm 0.5$ & $1.6 \pm 0.5$ & 0.077 \\
\hline Stent diameter $(\mathrm{mm})$ & $3.1 \pm 0.4$ & $3.0 \pm 0.4$ & 0.586 \\
\hline Lesion length (mm) & $27.3 \pm 9.1$ & $35.9 \pm 13.1$ & 0.013 \\
\hline Post-dilation (\%) & $5(17)$ & $6(35)$ & 0.275 \\
\hline Temporary pacing (\%) & $0(0)$ & $0(0)$ & 1.00 \\
\hline IABP (\%) & $6(20)$ & $2(12)$ & 0.751 \\
\hline Pre-procedure CK (U/L) & $542 \pm 823$ & $434 \pm 580$ & 0.644 \\
\hline Pre-procedure CK-MB ( $\mu \mathrm{g} / \mathrm{L})$ & $78 \pm 171$ & $25.9 \pm 42.6$ & 0.240 \\
\hline Pre-procedure c'TnI $(\mu \mathrm{g} / \mathrm{L})$ & $10.5 \pm 23.3$ & $9.8 \pm 18.7$ & 0.922 \\
\hline Peak CK (U/L) & $2513 \pm 1637$ & $2887 \pm 2319$ & 0.522 \\
\hline Peak CK-MB $(\mu \mathrm{g} / \mathrm{L})$ & $260 \pm 185$ & $248 \pm 238$ & 0.852 \\
\hline Peak cTnI $(\mu \mathrm{g} / \mathrm{L})$ & $99.0 \pm 78.1$ & $107 \pm 125$ & 0.788 \\
\hline
\end{tabular}

Data are presented as $\mathrm{n}(\%)$ or the mean $\pm \mathrm{SD}$. Unheralded group: patients with de novo symptoms of STEMI; heralded group: patients had symptoms before STEMI. LM: left main artery; LAD: left anterior descending artery; LCX: left circumflex artery; RCA: right coronary artery.

\section{Correlational and Receiver Operating Characteristic Analysis}

No correlations were found among HNP1-3, LL-37 and hs-CRP either systemically (aortic root) or locally (culprit artery) (all $p>0.05$ ), and systemic HNP1-3 and LL-37 were not associated with WBC or subset counts in STEMI (all $p>0.05$ ) (Table 4). There were no associations among systemic (peripheral venous) HNP1-3, LL-37 and hs-CRP on days $0,1,3$, and 5 following STEMI (all $p>0.05$ ), and systemic HNP1-3 or LL-37 levels were not correlated with WBC or subset counts at those time points (all $p>$ 0.05) (Table 5). In addition, plasma HNP1-3 and LL-37 were not correlated with triglyceride (TG), total cholesterol (TC), low density lipoprotein cholesterol (LDL-C), high density lipoprotein cholesterol (HDL-C) or Lp(a) levels (Table 6). Although systemic and local hs-CRP did not correlate with TG, TC,
LDL-C or HDL-C levels, they were found to correlate with Lp(a) levels ( $r s=0.369, p=0.027 ; \quad r s=0.331$, $p=0.048$, respectively) (Table 6).

We further investigated whether plasma levels of hs-CRP, HNP1-3 or LL-37 could reflect the severity and duration of myocardial damage by correlational analysis. Parameters of the severity of myocardial damage (peak CK, peak CK-MB or peak cTnI) were not associated with plasma hs-CRP, HNP1-3 or LL-37 levels (all $p>0.05$ ) (Table 7); however, ischemia time in STEMI group correlated with systemic and local levels of HNP1-3 ( $r s=-0.360, p=0.013 ; r s=0.608$, $p=0.000$, respectively), and were also associated with systemic and local levels of hs-CRP ( $r s=0.408$, $p=0.004 ; r s=0.425, p=0.003$, respectively), but not with those of LL-37 (all $p>0.05$ ) (Table 7).

Receiver operating characteristic (ROC) analysis revealed that the best cutoff value for systemic 
A
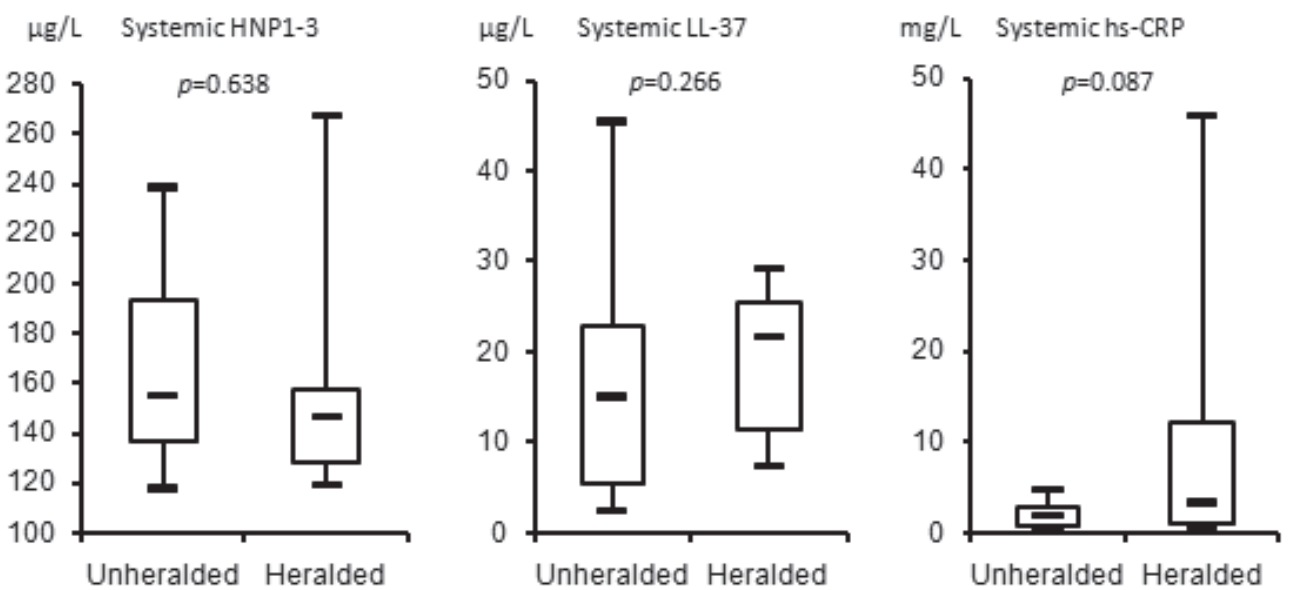

B
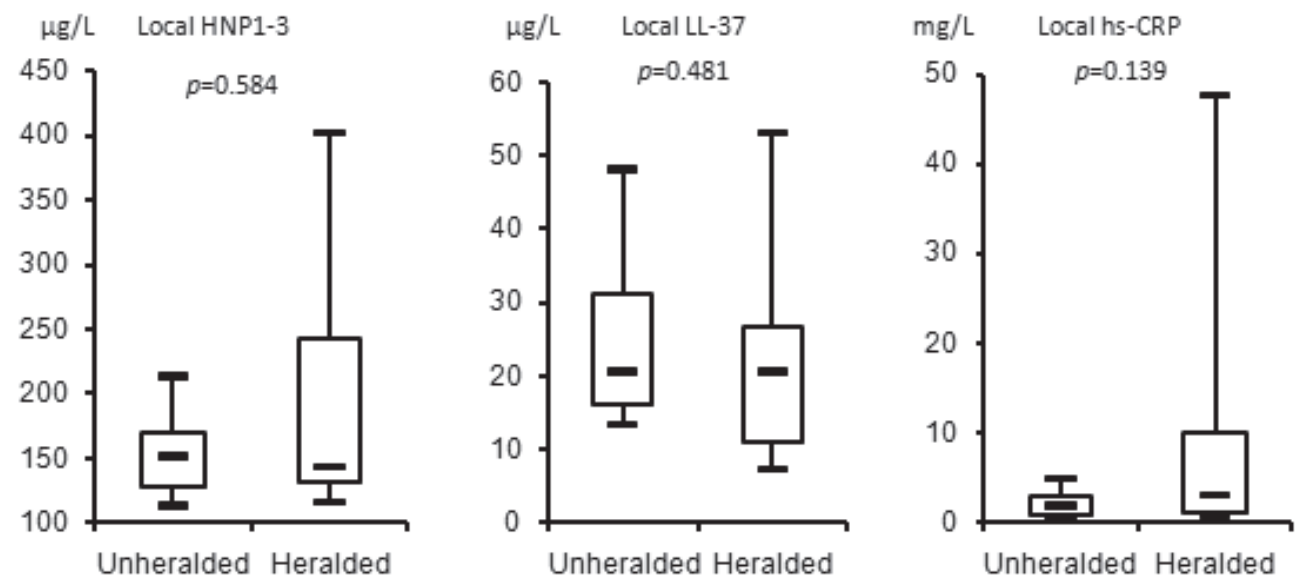

Fig. 3. Panel A: Comparisons of systemic plasma HNP1-3, LL-37 or hs-CRP levels between unheralded $(n=30)$ and heralded $(n=17)$ STEMI groups. Panel B: Comparisons of local plasma HNP1-3, LL-37 or hs-CRP between unheralded $(n=30)$ and heralded $(n=17)$ STEMI groups. Unheralded group means patients with de novo symptoms of STEMI; heralded group means patients had symptoms before STEMI. Medians and 10th, 25th, 75th and 90th percentiles are shown.

HNP1-3 levels discriminating STEMI from no CAD and stable CAD was $136 \mu \mathrm{g} / \mathrm{L}$ with a sensitivity of $77.2 \%$, a specificity of $66.7 \%$ and an area under the curve (AUC) of 0.717 (95\% CI: 0.624 to 0.811 ; $p=0.000$ ) (Fig. 6A); The best cutoff value for systemic LL-37 levels was $30.1 \mu \mathrm{g} / \mathrm{L}$ with a sensitivity of $87.2 \%$, a specificity of $46.7 \%$ and an AUC of 0.702 (95\% CI: 0.609 to $0.795 ; p=0.000$ ) (Fig. 6B).

\section{Discussion}

\section{Major Results}

There are two major findings in the current study: 1) systemic plasma LL-37 levels transiently decrease in STEMI patients relative to no CAD and stable CAD patients and are restored within 1 day, but local plasma LL-37 levels in the culprit lesion are higher than in the systemic circulation; and 2) systemic plasma HNP 1-3 levels increase in STEMI patients and are sustained, at least in the first week of STEMI. To the best of our knowledge, this is the first study to identify blood HNP1-3 and LL-37 changes associated with AMI. As systemic HNP1-3 or LL-37 levels did not associate with WBC or subset counts, it is likely that synthesis and/or release were persistently enhanced for HNP1-3, but transiently inhibited for LL-37 in STEMI. 
A

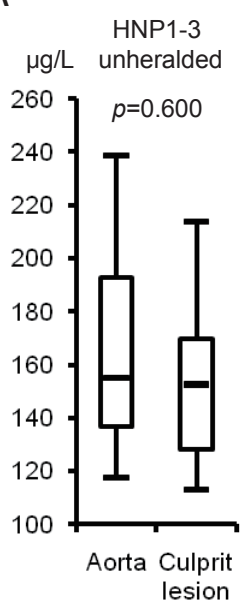

B

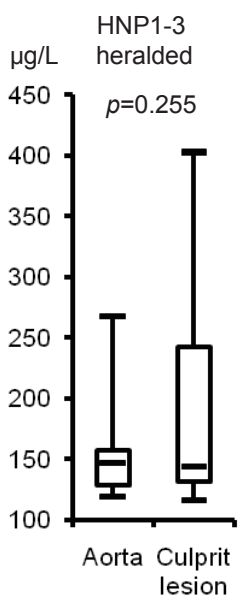

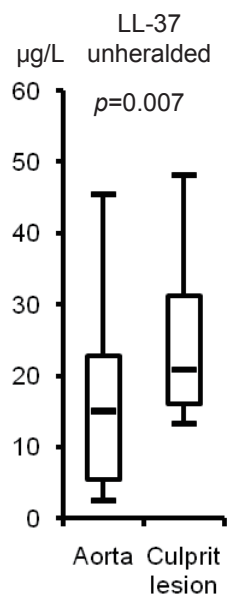
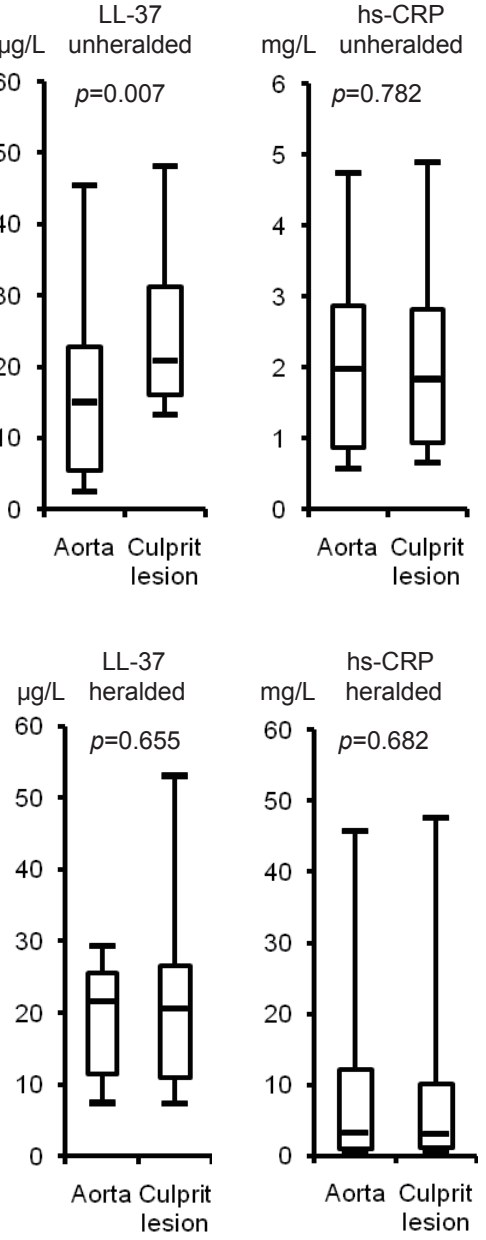

$\mu \mathrm{g} / \mathrm{L}$

HNP1-3

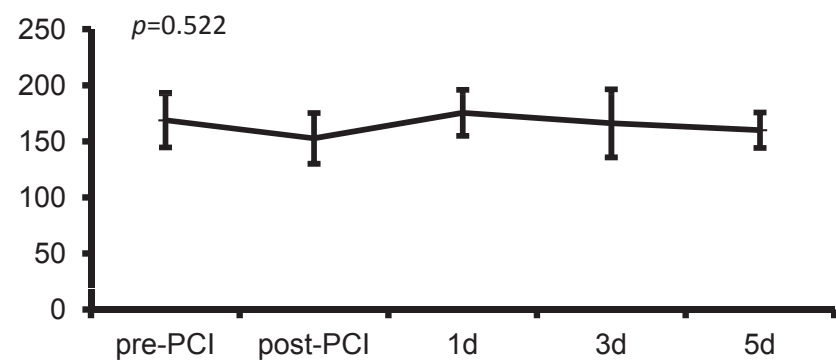

Fig. 4. Comparisons of plasma HNP1-3, LL-37 or hs-CRP levels between systemic and local sites in unheralded (panel A) and heralded (panel B) groups. Unheralded group: patients with de novo symptoms of STEMI $(n=30)$; heralded group: patients had symptoms before STEMI $(n=17)$. Medians and 10th, 25th, 75th and 90th percentiles are shown.

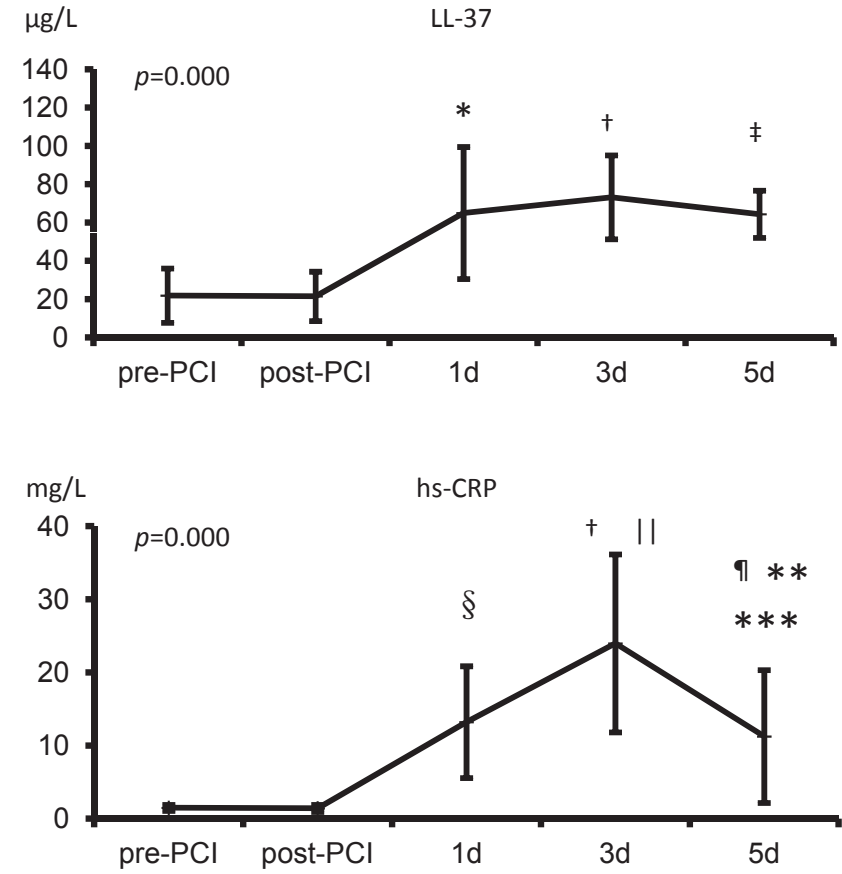

Fig.5. Time course changes of peripheral venous plasma HNP1-3, LL-37 and hs-CRP after STEMI $(n=6)$. ${ }^{*} p=0.001$ vs. pre-PCI and post-PCI, ${ }^{\dagger} p=0.000$ vs. prePCI and post-PCI, ${ }^{*} p=0.002$ vs. pre-PCI and postPCI; ${ }^{\S} p=0.013$ vs. pre-PCI and post-PCI, ${ }^{\|} p=0.022$ vs. $1 \mathrm{~d},{ }^{\natural} p=0.036$ vs. pre-PCI, ${ }^{* * *} p=0.034$ vs. postPCI, ${ }^{* *} p=0.008$ vs. $3 \mathrm{~d}$.

porarily prevented local LL-37 levels from dilution by blood flow. This notion is further supported by the fact that 1) the difference between local and systemic levels of LL-37 was seen in unheralded but not in heralded patients. In the latter, pre-infarction symptoms may reflect the process of intermittent occlusion before the final persistent occlusion. Systemic reduction of LL-37 may be triggered by pre-infarction events, but intermittent occlusion of the culprit vessel in the heralded group was unable to maintain local and systemic divergence; and 2) local LL-37 levels in the unheralded group did not correlate with culprit 
Table 4. Correlations among local plasma HNP1-3, LL-37 and hs-CRP levels and their associations with WBC or subset counts $(n=47)$

\begin{tabular}{lccccccc}
\hline & HNP1-3 & LL-37 & hs-CRP & WBC & Neutrophil & Lymphocyte & Monocyte \\
\hline Systemic & & & & & & & \\
HNP1-3 & - & 0.278 & 0.163 & 0.625 & 0.621 & 0.929 & 0.812 \\
LL-37 & 0.278 & - & 0.774 & 0.541 & 0.349 & 0.310 & 0.528 \\
hs-CRP & 0.168 & 0.774 & - & & & & \\
Local & & & & & & & \\
HNP1-3 & - & 0.856 & 0.817 & & & & \\
LL-37 & 0.856 & - & 0.845 & & & & \\
hs-CRP & 0.817 & 0.845 & - & & & & \\
\hline
\end{tabular}

$p$ values of Spearman's correlation are presented.

Table 5. Correlations among peripheral plasma HNP1-3, LL-37 and hs-CRP levels and their associations with WBC or subset counts on days $0,1,3$ and 5 time points following STEMI $(n=6)$

\begin{tabular}{lcccccc}
\hline & LL-37 & hs-CRP & WBC & Neutrophil & Lymphocyte & Monocyte \\
\hline HNP1-3 & & & & & & \\
Od (pre-PCI) & 0.073 & 0.403 & 0.121 & 0.805 & 0.841 & 0.294 \\
Od (post-PCI) & 0.419 & - & - & - & - & - \\
1d & 0.320 & 0.691 & 0.056 & 0.744 & 0.944 & 0.567 \\
3d & 0.788 & 0.749 & 0.994 & 0.777 & 0.826 & 0.988 \\
5d & 0.081 & 0.171 & 0.244 & 0.288 & 0.537 & 0.883 \\
LL-37 & - & & & & & \\
Od (pre-PCI) & - & 0.201 & 0.149 & 0.551 & 0.588 & 0.088 \\
Od (post-PCI) & - & - & - & - & - & - \\
1d & - & 0.347 & 0.940 & 0.819 & 0.944 & 0.261 \\
3d & - & 0.887 & 0.265 & 0.320 & 0.208 & 0.537 \\
5d & - & 0.449 & 0.203 & 0.566 & 0.470 & 0.299 \\
\hline
\end{tabular}

$p$ values of correlation analysis are presented.

lesion length $(p=0.229)$ or reference vessel diameter $(p=0.202)$ (data not shown), which at least partially reflects the volume of plaque and thrombus complex. This could exclude the possibility that local release of LL-37 in the unheralded group was more excessive than in the heralded group, although the former had a longer culprit lesion than the latter.

LL-37 has been found in infiltrating macrophages and in some endothelial cells (ECs) in atherosclerotic lesions ${ }^{14,15)}$. It may induce ICAM-1 and MCP-1 expression in cultured HUVECs ${ }^{14)}$, and induce apoptosis of cultured VSMCs, which is known to be implicated in plaque rupture ${ }^{15)}$. PR-39, a cathelicidin family member in pigs, has been reported to play cardioprotective roles, such as limiting infarction size and proangiogenic function ${ }^{16,17)}$; however, there is lack of sequence and structural similarities between LL-37 and PR-39 ${ }^{16)}$. Thus, it is still unclear whether transient down-regulation of plasma LL-37 in AMI has beneficial effects. Park et al. ${ }^{18)}$ reported that LL-37 protein expression was lower in keloid tissue than in normal skin and LL-37 inhibited collagen production in human dermal fibroblasts, suggesting that LL-37 may have antifibrotic action during the wound repair process. LL-37 may also induce fibroblast proliferation, which contributes to tissue repair ${ }^{19)}$. Moreover, the chorioallantoic membrane assay and a rabbit model of hind-limb ischemia indicated that LL-37 stimulates physiologic and pathologic angiogenesis and arteriogenesis ${ }^{20)}$. Thus, decreased LL-37 in the circulation may be associated with plaque rupture and cardiac remodeling following AMI.

\section{Human Neutrophil Peptide 1-3 and Acute Myocardial Infarction}

The present study showed that STEMI group had the highest levels of HNP 1-3, followed by the stable $\mathrm{CAD}$ group and then the no CAD group. This indi- 
Table 6. Correlational analysis of systemic plasma HNP1-3, LL-37 and hs-CRP with lipid profile and lipoprotein(a) $(n=47)$

\begin{tabular}{|c|c|c|c|c|c|}
\hline & TG & $\mathrm{TC}$ & LDL-C & HDL-C & $\mathrm{Lp}(\mathrm{a})$ \\
\hline \multicolumn{6}{|l|}{ Systemic } \\
\hline hs-CRP & 0.380 & 0.910 & 0.562 & 0.940 & $0.027, r s=0.369$ \\
\hline HNP1-3 & 0.794 & 0.490 & 0.350 & 0.099 & 0.231 \\
\hline LL-37 & 0.521 & 0.201 & 0.142 & 0.254 & 0.804 \\
\hline \multicolumn{6}{|l|}{ Local } \\
\hline hs-CRP & 0.586 & 0.990 & 0.600 & 0.881 & $0.048, r s=0.331$ \\
\hline HNP1-3 & 0.988 & 0.708 & 0.603 & 0.107 & 0.333 \\
\hline LL-37 & 0.217 & 0.136 & 0.261 & 0.478 & 0.408 \\
\hline
\end{tabular}

$p$ values of Spearman's correlation are presented. TG, triglyceride; TC, total cholesterol; LDL-C, low density lipoprotein cholesterol; HDL-C, high density lipoprotein cholesterol; Lp(a), lipoprotein(a).

Table 7. Correlational analysis of plasma HNP1-3, LL-37 and hs-CRP with lesion length, ischemia time or myocardial markers $(n=47)$

\begin{tabular}{lcccccc}
\hline & $\begin{array}{c}\text { Systemic } \\
\text { hs-CRP }\end{array}$ & $\begin{array}{c}\text { Systemic } \\
\text { HNP1-3 }\end{array}$ & $\begin{array}{c}\text { Systemic } \\
\text { LL37 }\end{array}$ & $\begin{array}{c}\text { Local } \\
\text { hs-CRP }\end{array}$ & $\begin{array}{c}\text { Local } \\
\text { HNP1-3 }\end{array}$ & $\begin{array}{c}\text { Local } \\
\text { LL37 }\end{array}$ \\
\hline Peak-CK & 0.619 & 0.233 & 0.873 & 0.444 & 0.948 & 0.512 \\
Peak-CK-MB & 0.215 & 0.098 & 0.549 & 0.359 & 0.878 & 0.594 \\
Peak-cTnI & 0.858 & 0.305 & 0.993 & 0.434 & 0.612 & 0.984 \\
Ischemia time & $0.004, r s=0.408$ & $0.013, r s=-0.360$ & 0.381 & $0.003, r s=0.425$ & $0.000, r s=0.608$ & 0.295 \\
\hline
\end{tabular}

$p$ values of Spearman's correlation analysis are presented.

cates that baseline circulating HNP1-3 may be chronically elevated in CAD and further increased in the acute phase of AMI. Attention has been paid to HNP13 , which is supposed to serve as a link between inflammation and atherosclerosis and is a potential therapeutic target in cardiovascular diseases $(\mathrm{CVD})^{4,21,22)}$; however, there is still a lack of data regarding circulating HNP levels in CAD. Accumulation of HNP1-3 proteins in atherosclerotic vessel walls was found in ECs, VSMCs and extracellular matrix, and this seems to be through a diffusion mechanism by binding HNP1-3 to ECs, SMCs and extracellular matrix ${ }^{6,11,23-25)}$. Thus, chronic elevation of blood HNP1-3 may contribute to its excessive deposition in the vessel wall.

Current opinion inclines to an atherogenic role of HNP1-3. In addition to its impairment roles in endothelial function, it may favor atherosclerosis by the modulation of LDL and $\operatorname{Lp}(\mathrm{a})$ metabolism $^{6,8,25)}$. Nassar et $a l_{.}{ }^{22)}$ reported that the amount of HNP1-3 in skin is an independent predictor of the likelihood and severity for CAD in the male gender. Our results thus provided new evidence for the association between HNP1-3 and CAD. As HNP1-3 binds to fibrin and plasminogen, affecting the binding of plasminogen to fibrin and inhibiting tissue-type plasminogen activator and plasminogen-mediated fibrinolysis in a dose-dependent manner ${ }^{10,11)}$, it is probable that plasma HNP1-3 elevation is involved in thrombogenesis at the site of a culprit lesion in AMI. Furthermore, HNP1-3 may serve as a clinical risk marker for CVDrelated morbidity and mortality in type 1 diabetes $^{26)}$; however, its usefulness for risk stratification and its prognostic value are still unknown for patients with CAD, especially those with myocardial infarction.

\section{Prospective Value of Plasma Human Neutrophil Peptide 1-3 and LL-37 for Acute Myocardial Infarction}

It is known that ischemia of significant duration that induces infarction results in an inflammatory response ${ }^{27)}$. Our study found that the ischemia time in STEMI correlate positively with systemic hs-CRP but negatively with systemic HNP1-3. We think this is reasonable and explainable. Unlike systemic hs-CRP levels peaked within 5 days after STEMI, the peak of systemic HNP1-3 was not detected during the period. This indicates that systemic HNP1-3 possibly peaks and then decreases to relatively higher levels prior to the onset of STEMI. This suggests that HNP1-3 probably has similar properties to CRP, which may not only contribute to the progression of CAD, but also serve as a systemic biomarker for predicting future 
A

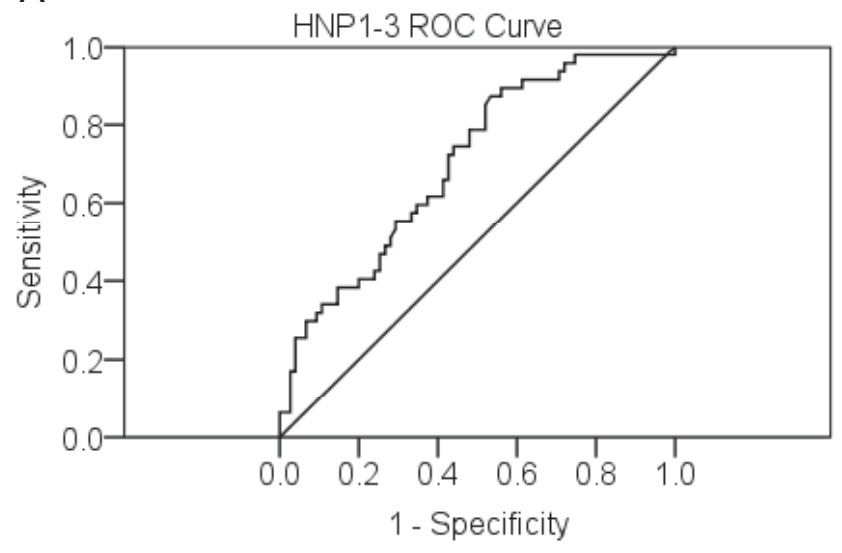

B

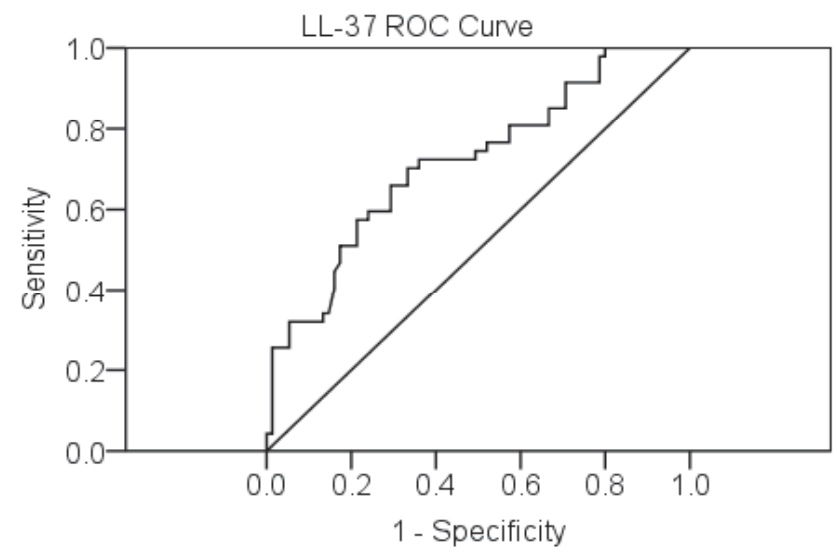

Fig. 6. Receiver operating characteristic (ROC) curve analysis. Pannel A: ROC curve for HNP1-3 and STEMI, AUC 0.717 (95\% CI: 0.624 to $0.811 ; p=0.000)$; Panel B: ROC curve for LL-37 and STEMI. AUC 0.702 (95\% CI: 0.609 to $0.795 ; p=0.000)$.

ischemic events in CAD patients ${ }^{1)}$. In addition, some inflammatory markers, such as IL-10, are modulators for healing and repair of the infarcted myocardium, and promoting more effective tissue repair may reduce deleterious remodeling, which is the leading cause of heart failure and death after AMI ${ }^{27)}$. As LL-37 is involved in tissue healing and repair ${ }^{18-20)}$, plasma LL-37 levels may be useful for predicting future cardiac events related to remodeling. Furthermore, the combination of blood HNP1-3 and LL-37 measurement, or together with other blood parameters, such as CRP, is possibly a multi-biomarker strategy for prognosis in patients with myocardial infarction.

\section{Study Limitations}

There are some limitations of our study. First, non-ST segment elevation acute coronary syndrome
(NSTEACS) is not included. As NSTEACS is generally caused by partial or intermittent occlusion, we did not expect there would be a measurable discrepancy of HNP1-3 or LL-37 between systemic and local circulation. Second, females were excluded. These issues should be addressed in future studies. Finally, manual aspiration catheters may be less powerful to prevent local samples from dilution due to partial blood flow restoration after the device crosses the lesion than aspiration and distal balloon occlusion systems ${ }^{3)}$.

\section{Conclusion}

Transiently decreased LL-37 and persistently increased HNP1-3 in the systemic circulation may associate with the pathophysiology of AMI, and ischemia time in STEMI correlates with plasma HNP1-3 levels. The diagnostic accuracy of HNP1-3 and LL-37 for STEMI was moderate and future studies should be directed to their prognostic values in acute coronary syndromes.

\section{Acknowledgements}

This study was supported by Beijing Natural Science Foundation (No.7082030) to Professor Hongbing Yan, Youxiurencai Fundation from the Beijing Government (No.20081D0300600080) and Clinicalbasic Cooperation Foundation from the Capital Medical University (No.2007JL42) to Doctor Hanjun Zhao.

\section{References}

1) Libby P, Okamoto $Y$, Rocha VZ, Folco E: Inflammation in atherosclerosis: transition from theory to practice. Circ J, 2010; 74: 213-220

2) De Servi S, Mariani M, Mariani G, Mazzone A: C-reactive protein increase in unstable coronary disease cause or effect? J Am Coll Cardiol, 2005; 46: 1496-1502

3) Maier W, Altwegg LA, Corti R, Gay S, Hersberger M, Maly FE, Sutsch G, Roffi M, Neidhart M, Eberli FR, Tanner FC, Gobbi S, von Eckardstein A, Luscher TF: Inflammatory markers at the site of ruptured plaque in acute myocardial infarction: locally increased interleukin- 6 and serum amyloid A but decreased C-reactive protein. Circulation, 2005; 111: 1355-1361

4) Kougias P, Chai H, Lin PH, Yao Q, Lumsden AB, Chen C: Defensins and cathelicidins: neutrophil peptides with roles in inflammation, hyperlipidemia and atherosclerosis. J Cell Mol Med, 2005; 9: 3-10

5) Li Y: The role of antimicrobial peptides in cardiovascular physiology and disease. Biochem Biophys Res Commun, 2009; 390: 363-367

6) Bdeir K, Cane W, Canziani G, Chaiken I, Weisel J, Kos- 
chinsky ML, Lawn RM, Bannerman PG, Sachais BS, Kuo A, Hancock MA, Tomaszewski J, Raghunath PN, Ganz T, Higazi AA, Cines DB: Defensin promotes the binding of lipoprotein(a) to vascular matrix. Blood, 1999; 94: 20072019

7) He C, Huang R, Du F, Zheng F, Wei L, Wu J: LDL oxidation by THP-1 monocytes: implication of HNP-1, SgIII and DMT-1. Clin Chim Acta, 2009; 402: 102-106

8) Kougias P, Chai H, Lin PH, Yao Q, Lumsden AB, Chen $\mathrm{C}$ : Neutrophil antimicrobial peptide alpha-defensin causes endothelial dysfunction in porcine coronary arteries. J Vasc Surg, 2006; 43: 357-363

9) Nassar T, Akkawi S, Bar-Shavit R, Haj-Yehia A, Bdeir K, Al-Mehdi AB, Tarshis M, Higazi AA: Human alphadefensin regulates smooth muscle cell contraction: a role for low-density lipoprotein receptor-related protein/alpha 2-macroglobulin receptor. Blood, 2002; 100: 4026-4032

10) Higazi AA, Barghouti II, Abu-Much R: Identification of an inhibitor of tissue-type plasminogen activator-mediated fibrinolysis in human neutrophils. A role for defensin. J Biol Chem, 1995; 270: 9472-9477

11) Higazi AA, Ganz T, Kariko K, Cines DB: Defensin modulates tissue-type plasminogen activator and plasminogen binding to fibrin and endothelial cells. J Biol Chem, 1996; 271: 17650-17655

12) Bokarewa M, Tarkowski A: Human alpha -defensins neutralize fibrinolytic activity exerted by staphylokinase. Thromb Haemost, 2004; 91: 991-999

13) Chavakis T, Cines DB, Rhee JS, Liang OD, Schubert U, Hammes HP, Higazi AA, Nawroth PP, Preissner KT, Bdeir K: Regulation of neovascularization by human neutrophil peptides (alpha-defensins): a link between inflammation and angiogenesis. FASEB J, 2004; 18: 1306-1308

14) Edfeldt K, Agerberth B, Rottenberg ME, Gudmundsson GH, Wang XB, Mandal K, Xu Q, Yan ZQ: Involvement of the antimicrobial peptide LL-37 in human atherosclerosis. Arterioscler Thromb Vasc Biol, 2006; 26: 15511557

15) Ciornei CD, Tapper H, Bjartell A, Sternby NH, Bodelsson M: Human antimicrobial peptide LL-37 is present in atherosclerotic plaques and induces death of vascular smooth muscle cells: a laboratory study. BMC Cardiovasc Disord, 2006; 6: 49

16) Zanetti M: The role of cathelicidins in the innate host defenses of mammals. Curr Issues Mol Biol, 2005; 7: 179-196

17) Haider H, Akbar SA, Ashraf M: Angiomyogenesis for myocardial repair. Antioxid Redox Signal, 2009; 11: $1929-1944$
18) Park HJ, Cho DH, Kim HJ, Lee JY, Cho BK, Bang SI, Song SY, Yamasaki K, Di Nardo A, Gallo RL: Collagen synthesis is suppressed in dermal fibroblasts by the human antimicrobial peptide LL-37. J Invest Dermatol, 2009; 129: 843-850

19) Tomasinsig L, Pizzirani C, Skerlavaj B, Pellegatti P, Gulinelli S, Tossi A, Di Virgilio F, Zanetti M: The human cathelicidin LL-37 modulates the activities of the P2X7 receptor in a structure-dependent manner. J Biol Chem, 2008; 283: 30471-30481

20) Koczulla R, von Degenfeld G, Kupatt C, Krotz F, Zahler S, Gloe T, Issbrucker K, Unterberger P, Zaiou M, Lebherz C, Karl A, Raake P, Pfosser A, Boekstegers P, Welsch U, Hiemstra PS, Vogelmeier C, Gallo RL, Clauss M, Bals R: An angiogenic role for the human peptide antibiotic LL-37/hCAP-18. J Clin Invest, 2003; 111: 1665-1672

21) Quinn K, Henriques M, Parker T, Slutsky AS, Zhang H: Human neutrophil peptides: a novel potential mediator of inflammatory cardiovascular diseases. Am J Physiol Heart Circ Physiol, 2008; 295: H1817-H1824

22) Nassar H, Lavi E, Akkawi S, Bdeir K, Heyman SN, Raghunath PN, Tomaszewski J, Higazi AA: alpha-Defensin: link between inflammation and atherosclerosis. Atherosclerosis, 2007; 194: 452-457

23) Barnathan ES, Raghunath PN, Tomaszewski JE, Ganz T, Cines DB, Higazi AA: Immunohistochemical localization of defensin in human coronary vessels. Am J Pathol, 1997; 150: 1009-1020

24) Higazi AA, Lavi E, Bdeir K, Ulrich AM, Jamieson DG, Rader DJ, Usher DC, Kane W, Ganz T, Cines DB: Defensin stimulates the binding of lipoprotein (a) to human vascular endothelial and smooth muscle cells. Blood, 1997; 89: 4290-4298

25) Higazi AA, Nassar T, Ganz T, Rader DJ, Udassin R, Bdeir K, Hiss E, Sachais BS, Williams KJ, Leitersdorf E, Cines DB: The alpha-defensins stimulate proteoglycan-dependent catabolism of low-density lipoprotein by vascular cells: a new class of inflammatory apolipoprotein and a possible contributor to atherogenesis. Blood, 2000; 96: 1393-1398

26) Joseph G, Tarnow L, Astrup AS, Hansen TK, Parving $\mathrm{HH}$, Flyvbjerg A, Frystyk J: Plasma alpha-defensin is associated with cardiovascular morbidity and mortality in type 1 diabetic patients. J Clin Endocrinol Metab, 2008; 93: $1470-1475$

27) Frangogiannis NG, Smith CW, Entman ML: The inflammatory response in myocardial infarction. Cardiovasc Res, 2002; 53: 31-47 